\section{Renal impairment associated with non-steroidal anti-inflammatory drugs}

SIR, The study by Unsworth et al ${ }^{\prime}$ would appear to have methodological deficiencies which limit both its conclusions and its applicability to rheumatic patients taking nonsteroidal anti-inflammatory drugs (NSAIDs). These include the reason for choosing to discontinue the medication in a particular individual: the lack of information about the reason for admission of the patients, and particularly their state of hydration, and stability of renal function compared with previous estimations; the variable time before discharge or reintroduction of NSAIDs, which results in distortion of the slopes in Fig. 2, in which the serum creatinine and urea graphs include results of patients 23-27 who are not referred to anywhere else in the article; the reliance on creatinine clearance as a measure of renal function, with its inherent inaccuracies (two validations with CrEDTA out of 22 estimations are not sufficient reassurance); and the lack of randomisation.

Middlemore Hospital,

PETER J GOW

Private Bag,

Otahuhu,

Auckland 6,

New Zealand

\section{Reference}

1 Unsworth J. Sturman S. Lunec J. Blake D R. Renal impairment associated with non-steroidal anti-inflammatory drugs. Ann Rheum Dis 1987: 46: 233-6.

SIR. Perhaps we did not clearly explain some of the points that $\mathrm{Dr}$ Gow raises in his letter: NSAID ingestion is increasingly recognised as a cause of renal failure: our patients show reversible renal suppression. We feel that this observation is applicable to all patients taking these drugs. Our patients were admitted sequentially from a waiting list for treatment or assessment of their rheumatological condition(s), and this is of no relevance to the ensuing discussion. They volunteered to stop NSAIDs to assess the effect of withdrawal of these drugs on renal function. That their length of stay and tolerance to NSAID removal would be variable is obvious. We clearly state that, unless described in the text, all recognised predispositions to NSAID nephrotoxicity had been excluded. and dehydration is referenced in this context. The inclusion of patients 23-27 is an illustrative error and has no bearing on this or previous discussions; they form part of a different study and our statistics do not include these data. Creatinine clearances remain the best method commonly available for the measurement of renal function. The fact that they change significantly and consistently is the message that we have tried to get across. Our aim in publishing this small study, which poses more questions than it answers, is to alert NSAID prescribers to possibly common side effects, and we feel that renal monitoring should be considered in all patients receiving these drugs.

Rheumatism Research Wing,

J UNSWORTH

The Medical School,

Brirmingham B15 2TJ

D R BLAKE

\section{Rheumatoid factor in patients with systemic lupus erythematosus}

SIR, In the report by Helin et al in the Annals ${ }^{1}$ the authors suggest that rheumatoid factor (RF) protects against nephropathy in patients with systemic lupus erythematosus (SLE).

We have reviewed our series of 78 patients with SLE fulfilling the criteria of the above report for evaluating nephropathy and assaying RF. The Waaler-Rose sensitised sheep cell agglutination test was used to measure RF, with titres equal or greater than 1/64 considered positive. Both groups with and without renal disease were comparable for age and sex. A renal biopsy was performed in 38 out of 40 patients with nephropathy. The results are shown in Table 1.

Table 1 Rheumatoid factor and nephropathy in SLE*

\begin{tabular}{lllc}
\hline & $\begin{array}{l}\text { With } \\
\text { nephropathy }\end{array}$ & $\begin{array}{l}\text { Without } \\
\text { nephropathy }\end{array}$ & Total \\
\hline RF (+) & 4 & 5 & 9 \\
RF (-) & 36 & 33 & 69 \\
Total & 40 & 38 & 78 \\
$\%$ RF (+) & 10 & $13 \cdot 1$ & $11 \cdot 5$ \\
\hline
\end{tabular}

${ }^{*}$ Numbers of patients are given.

Our results differ from those obtained by Helin et al, ${ }^{1}$ Davis and Bollet, ${ }^{2}$ and Hill et al, ${ }^{3}$ and agree with those obtained by Kantor et $a l^{4}$ and Baldwin et al. ${ }^{5}$ We found no significant difference between the percentages of positive RF in the groups with or without nephropathy. In addition, in the four cases with renal disease and RF $(+)$ the renal biopsy specimens showed severe morphological lesions (three cases of diffuse proliferative glomerulonephritis and one case of membranous glomerulonephritis).

The discrepancy between these studies does not permit definite conclusions to be reached about the role of RF in the aetiopathogenesis of SLE nephropathy.

${ }^{\text {'Servicio de Medicina Interna ROSA MORENO PINILLOS }}{ }^{1}$ and ${ }^{2}$ Sección de

Reumatologia

Hospital de Bellvitge, JOAN MIQUEL NOLLA i SOLE ${ }^{2}$ XAVIER JUANOLA i ROURA ${ }^{2}$ VISITACION PAC FERRAZ ${ }^{1}$

Universidad de Barcelona, ANTONIO VIDALLER PALACIN ${ }^{1}$ L'Hospitalet de Llobregat, ISABEL MOGA SAMPERE ${ }^{1}$ Barcelona 


\section{References}

1 Helin H. Korpela M. Mustonen J. Pasternack A. Rheumatoid factor in rheumatoid arthritis associated renal disease and in lupus nephritis. Ann Rheum Dis 1986: 45: 508-11.

2 Davis J S. Bollet A J. Complement levels. rheumatoid factor and renal disease in systemic lupus erythematosus (SLE). Arthritis Rheum 1966: 9: 499-500.

3 Hill G S. Hinglais N. Tron F. Bach J-F. Systemic lupus erythematosus. Morphologic correlations with immunologic and clinical data at the time of biopsy. Am J Med 1978: 64: 61-79.

4 Kantor G L. Bickel Y B. Barnett E V. Coexistence of systemic lupus erythematosus and rheumatoid arthritis. Am J Med 1969: 47: $433-44$

5 Baldwin D S. Lowenstein J. Rothfield N F. Gallo G. McCluskey R T. The clinical course of the proliferative and membranous forms of lupus nephritis. Ann Intern Med 1970; 73: $929-42$.

SIR, It is not surprising to see discrepant results on the occurrence of rheumatoid factors (RF) in patients with systemic lupus erythematosus with or without renal disease. In our report ${ }^{1}$ we discussed the issue and noted (Discussion, 1st paragraph, p. 510) that in previous studies, either a significant negative correlation ${ }^{2}{ }^{3}$ or no correlation ${ }^{45}$ was found. We also stated that the reason for this discrepancy is unclear. This is also the conclusion of Moreno et al in the light of their own results. The main thrust of our report was the occurrence of RF in patients with rheumatoid arthritis with or without renal disease, a topic much less dealt with in previous studies.

Departments of 'Biomedical and

${ }^{2}$ Clinical Sciences.

H HELIN ${ }^{1}$

University of Tampere.

Finland

Department of Medicine.

Tampere University Central Hospital.

M KORPEI.A Tampere.

Finland

\section{References}

1 Helin H. Korpela M. Mustonen J. Pasternack A. Rheumatoid factor in rheumatoid arthritis associated renal discase and in lupus nephritis. Ann Rheum Dis 1986: 45: 508-11.

2 Davis J S, Bollet A J. Complement levels, rheumatoid factor. and renal disease in systemic lupus erythematosus (SLE). Arthritis Rheum 1966: 9: 499-500).

3 Hill G S. Hinglais N. Tron F. Bach J-F. Systemic lupus erythematosus. Morphologic correlations with immunologic and clinical data at the time of biopsy. Am J Med 1978: 64: 61-79.

4 Kantor G L. Bickel Y B. Barnett E V. Coexistence of systemic lupus erythematosus and rheumatoid arthritis. Am J Med 1969 47: 433-44

5 Baldwin D S. Lowenstein J. Rothfield N F. Gallo G. McCluskey $R$ T. The clinical course of the proliferative and membranous forms of lupus nephritis. Ann Intern Med 1979: 73: $929-42$.

\section{Methylprednisolone pulse therapy in rheumatoid arthritis}

SIR, The paper entitled Combination of methylprednisol $\frac{\overline{\bar{c}}}{\overline{\mathrm{c}}}$ one pulse therapy and remission inducing drugs in rheumatoid arthritis' published in the Annals ${ }^{1}$ concludes that pulse therapy is of little or no value in the long term treatment ofes rheumatoid arthritis.

We believe that there are several deficiencies in this study and that the conclusions are not justified. To justify $\overrightarrow{-}$ such a conclusion the authors must ensure that a type If error has not occurred. There is no estimate of the powe of their study, but it is possible to calculate it. ${ }^{2}$ We estimate that their study would not be able to detect a 30\%क् difference between the two treatment groups because of the small numbers in each group. In fact there is a trend in $\overrightarrow{b_{0}}$ all their results which favours the active pulse group. This is further compounded by the fact that three different remission inducing drugs were used in each treatment group, which removes homogeneity of the treatment groups and adds another variable to the treatment pro $\overline{-}$ tocol. Also, although this is claimed to be a double blinco study, the fact that the first assessment was performed on to two weeks after treatment. when the patients receiving active pulse therapy showed significant disease sup@्D pression. means that the observer could not possibly blinded to the treatment the patient had received. As mis patients have disease duration of at least two years, du which time most of the erosive changes are known occur, it is hardly surprising that $x$ rays taken only eigh months after treatment failed to show any difference between the two treatment groups. The authors decided to delete error bars on their figures and not include an results from immune complex estimations, which makes i⿱ difficult for the reader to assess the results independently $\overrightarrow{\vec{\sigma}}$ Finally, no assessment was made at any stage, as to whether the two treatment groups were identical at the start of treatment. As a result of these deficiencies we believe that this paper has not justified the conclusions that the authors have drawn.

The question of whether initiation of pulse methyl prednisolone therapy at the start of treatment with remission inducing agent alters the efficacy or side effect of such an agent remains unanswered.

Flinders University of

South Australia

MALCOLM D SMITI요 PETER J ROBERTS-THOMSO 는

\section{References}

1 Hansen T M. Dickmeiss E, Jans H, Hansen T I. Ingeman Nielsen M. Lorenzen I B. Combination of methylprednisolone pulse therapy and remission inducing drugs in rhcumatoig arthritis. Ann Rheum Dis 1987; 46: 29(1-5.

2 Macuch R. Sim R. Sample size requirements for evaluating 6 conservative therapy. Cancer Treat Rep 1978; 62: 1037-40. (D)

SIR, Doctor Smith and his colleagues incorrectly quotē from the abstract of our paper that pulse therapy is of little 